\title{
Biological Activity of Moringa oleifera Lam. on Citrullus lanatus (Thunb.) in Sustainable Agriculture practices
}

\author{
Hoda Ahmed ${ }^{1,2}$, Salama El-Darier¹, Masrrat Migahid ${ }^{3}$ and Khansa Belkasem ${ }^{4}$ \\ 1Botany and Microbiology Department, Faculty of Science, Alexandria University, P.O. 21511 Alexandria, Egypt. \\ ${ }^{2}$ Biology Department, College of Science, King Faisal University, Al-Ahsa, P.O. 400 Al-Ahsa 31982, Kingdom of Saudi Arabia. \\ ${ }^{3}$ Biological and Geological Sciences Department, Faculty of Education, Alexandria University, P.O. 21526 Alexandria, Egypt. \\ ${ }^{4}$ Environmental Sciences and Natural Resources, Omar Al-Mokhtar University, P.O. 919 Bayda, Libya.
}

Correspondence Author: Hoda Ahmed, Biology Department, College of Science, King Faisal University, Al-Ahsa, P.O. 400 Al-Ahsa 31982, Kingdom of Saudi Arabia.

E-mail: haahmed@kfu.edu.sa

Received date: 20 May 2019, Accepted date: 20 July 2019, Online date: 28 July 2019

Copyright: (c) 2019 Hoda Ahmed et al., This is an open-access article distributed under the terms of the Creative Commons Attribution License, which permits unrestricted use, distribution, and reproduction in any medium, provided the original author and source are credited.

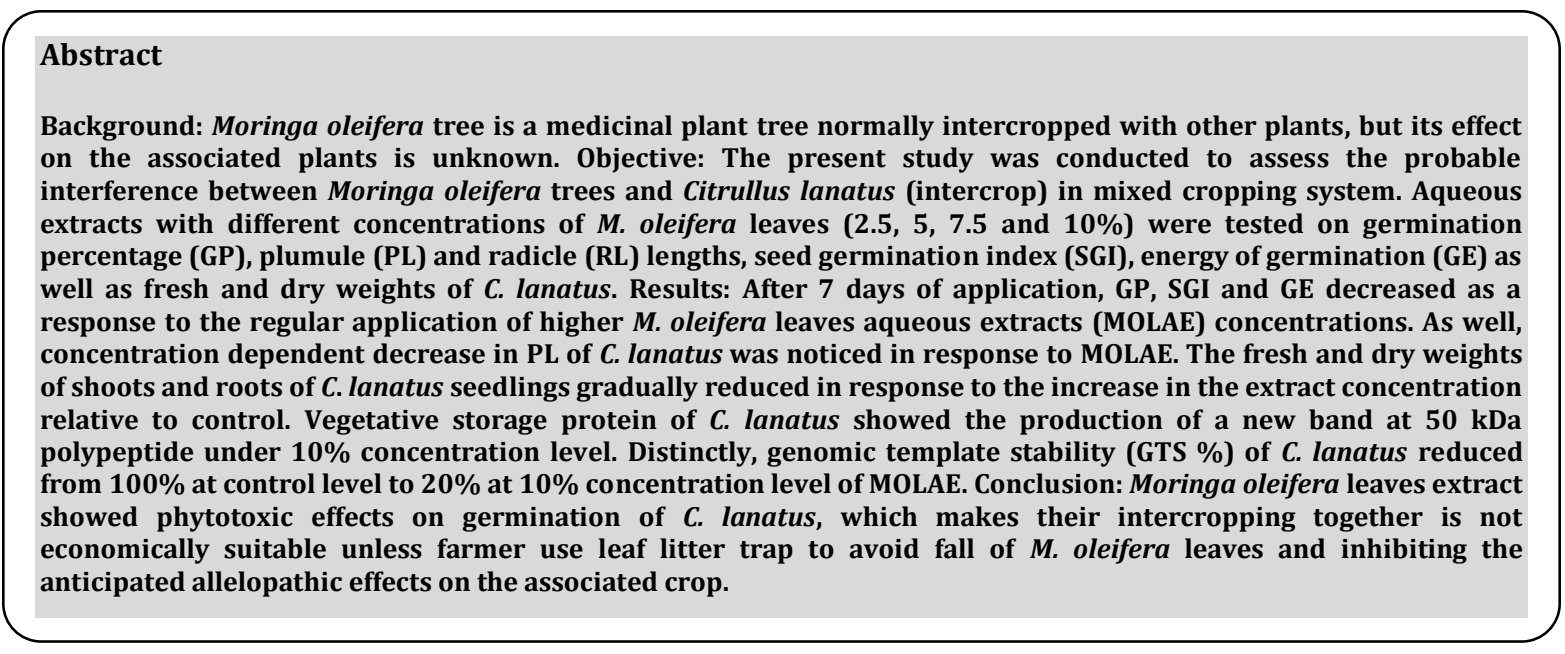

Keywords: Allelopathy, Moringa oleifera, Citrullus lanatus, Germination, Growth, Vegetative storage protein

\section{INTRODUCTION}

Sustainable farming is farming that is economically viable, highly productive, and environmentally sound and protects public health. Since four decades ago, crop yields in agricultural systems depended on internal resources and were modest, but stable. Production was safeguarded by growing more than one crop or variety in space and time in a field as insurance against severe weather. In orchards and trees ecosystems the use of cover crops promote soil fertility, soil structure, and water penetration, inhibit soil erosion, alter the microclimate and decrease weed competition as well as the use of herbicides [1,2,3]. Moringa oleifera Lam. is one of a potent source of several active ingredients like flavonoids, tannins, saponins, terpenoids, proanthocyanidins and cardiac glycosides which have tremendous therapeutic properties [4,5].

Intercropping is getting popularized in developing and developed countries for the best investment of land resources and reducing the risks of single crop failure [6]. In some intercropping system like cotton and sorghum, intercropping was observed to significantly reduce the weed density and dry matter as observed by Sathishkumar et al. [7]. Besides its benefits, great attention should be directed toward the undesirable chemical interfering (allelopathy) between the mixed crops, which is a unique behavior for each species. For example, seed germination and seedling growth of Lupinus termis are negatively affected by Nigella sativa seeds, which are commonly intercropped together [8]. Additionally, Abou-Zeid and El-Darier [9] confirmed the detrimental interaction of M. oleifera with Vicia faba and Zea mays. 
Furthermore, Ahangar et al. [10] suggested that the cultivation of neem and eucalyptus near agricultural fields is not recommended because of their adverse effects on crop productivity. Mona et al. [11] revealed that moringa leaves have allelopathic inhibitory effects on faba bean growth and should be removed from the field before its cropping. On the other hand, Kamran et al. [12] found that 3\% combined leaf extract of sorghum and moringa can be used to improve maize yield with good quality and cost-effective. Recently, Tahir et al. [13] postulated that $M$. oleifera extracts inhibited and stimulated the germination and seedling growth of Triticum aestivum and Sinapus arvensis.

Given sustainable development, economic and medicinal uses of $M$. oleifera, there is a growing interest in expanding the tree cultivation and propagation. Based on these, the probable allelopathic effect of $M$. oleifera should be estimated before its commercial cultivation with other crops, including watermelon. Therefore, the aim of the current work is to test the effect of different concentrations of $M$. oleifera leaves aqueous extracts (MOLAE) on the germination and seedling growth of Citrullus lanatus.

\section{MATERIALS AND METHODS}

\subsection{Collection of Plant Materials}

Leaves of $M$. oleifera as a donor species were newly harvested from polyculture fields distributed along the Alexandria-Cairo desert road during the year 2014. Seeds of $C$. lanatus as a recipient species were acquired from commercial and private seed store (SHAMA) at Alexandria. The seeds were surface cleaned and stored in glass jars at $5^{\circ} \mathrm{C}$ until use.

\subsection{Preparation of Moringa oleifera Leaves Aqueous Extract (MOLAE)}

Samples of the plant materials were washed with tap and distilled water, air-dried then cut into small pieces and ground to powder. The aqueous stock extract was obtained by soaking $100 \mathrm{~g}$ of the air-dried donor plant materials in one liter of distilled water at room temperature $\left(20 \pm 2^{\circ} \mathrm{C}\right)$ for 24 hours with occasional shaking. The mixture was filtered and the purified extract was adjusted to $\mathrm{pH} 6.8$ with $\mathrm{NaOH} 10 \%$. Under such an optimal pH, no significant growth inhibition occurs [14, 15]. Subsequent dilutions $(2.5,5,7.5$ and $10 \%)$ were prepared from the stock solution in addition to the control (distilled water).

\subsection{Preparation of Seeds for Germination Bioassay}

Seeds of $C$. lanatus were soaked in distilled water to test their viability and the precipitated seeds were air-dried at room temperature. The seeds were surface-sterilized for 5 minutes in a diluted solution of sodium hypochlorite (5\%), washed thoroughly with running water and then washed with distilled water for at least 5 times.

\subsection{Germination Bioassay}

The potential allelopathic effects of $M$. oleifera leaves on $C$. lanatus were studied using different aqueous extract concentrations $(2.5,5,7.5$ and $10 \%)$ as substrate medium for the germinating seeds. The seeds were germinated in Petri dishes (9$\mathrm{cm}$ diameter) on two discs of Whatman No.1 filter paper under normal laboratory conditions with day temperature ranging from $20-22^{\circ} \mathrm{C}$ and night temperature from $14-16^{\circ} \mathrm{C}$ and $10 \mathrm{ml}$ of each level of the donor species extracts were added. Treatments were arranged in a complete randomized block design with three replications. Measurements of germination percentage (GP), plumule (PL) and radicle (RL) lengths were recorded daily along 7 days.

\section{Calculations}

1. Phytotoxicity (PT) was calculated for each concentration treatment according to the general equation:

Phytotoxicity $=[1-($ allelopathic $/$ control) 100$]$

Where: Allelopathic $=$ number of germinated seeds for each treatment

2. Seed germination index (SGI) was calculated according to the following equation [16].

$\mathrm{SGI}=\Sigma \mathrm{Ti} \mathrm{Ni} / \mathrm{S}$

Where,

$\mathrm{Ti}=$ is the number of days after sowing

$\mathrm{Ni}=$ is the number of seeds germinated on the day $\mathrm{i}$

$\mathrm{S}=$ is the total number of seeds planted

3. The energy of germination (GE) was recorded, according to Farooq et al. [17] on the $4^{\text {th }}$ day after sowing. It is the percentage of germinating seeds (GP) four days after sowing relative to the total number of seeds tested (TNST).

$\mathrm{GE}=\mathrm{GP}\left(4^{\text {th }}\right.$ day $) / \mathrm{TNST}$

\subsection{Growth Bioassay}

A pot experiment was carried out in three replicates to test the effect of the different concentrations $(2.5,5$ and $10 \%)$ of $M$. oleifera leaves crude powder (MOLCP) besides the control on fresh and dry weights as well as the percentage of water content. The experiment was continued to test the maximum extract concentration (10\%) of MOLCP on protein profile in $C$. lanatus seedlings in sandy clay loam soil.

\subsection{Soil Analysis}


Six Soil samples from the natural sites where the alleged materials allelopathic are not deposited were used to execute the growth experiment. The samples were analyzed for some of their chemical and physical properties, according to Allen et al. [18].

\subsection{Implantation}

Ten seeds from $C$. lanatus were sown in plastic pot $15 \mathrm{~cm}$ diameter and $14 \mathrm{~cm}$ height $(1 \mathrm{~kg}$ soil) with sandy clay loam soil. The experiment was performed under normal laboratory conditions with day temperature ranging from $20-22^{\circ} \mathrm{C}$, light duration was 12 hours and light intensity was 1350 foot-candle. The plants were watered every two days on the average with normal tap water. Pots were carefully irrigated from the top the first time and sub-irrigated after that to avoid seedling disturbance. The amount of water corresponding to average soil-plant-transpiration calculated from water loss over a 24-hours interval was applied for soil in three replicates. Seedlings of the recipient species were harvested 21 days after sowing. One treatment was run as control without any addition of donor species crude powder.

Five complete morphologically homogenous $C$. lanatus seedlings from each treatment was excavated, washed by running water to remove adhering soil particles, then by distilled water. The samples were weighted fresh than dried at $65^{\circ} \mathrm{C}$ till constant weight to determine the dry weight of seedling and calculation of tissue water content.

\subsection{Protein Electrophoresis}

Sodium dodecyl sulphate polyacrylamide gel electrophoresis (SDS-PAGE) was performed to distinguish and fragment vegetative storage protein for treated C. lanatus samples, according to Laemmli [19].

\subsection{Statistical Treatment of Data}

Data collected on different parameters were analyzed statistically by using the COSTAT 2.00 statistical analysis software manufactured by Co-Hort Software Company. For analysis of variance and means data were separated using Fisher's protected least significant difference (LSD) test at 5\% probability level [20]. To account for possible differences in the interdependence of different parameters, a simple linear regression model was applied [21].

\section{RESULTS}

\subsection{Germination Bioassay}

The allelopathic effects of MOLAE on germination percentage (GP) of Citrullus lanatus are represented in Figure 1a. Notably, GP was significantly decreased with the increase in extract concentration 7 days after sowing, especially at 7.5 and $10 \%$ compared to control. Phytotoxicity (PT) percentages were remarkably different in response to the increase in MOLAE from 2.5 to $10 \%$ (Figure 1b). Extract concentration of 2.5, 7.5 and 10\% attained PT values of 11.11, 44.44 and $77.78 \%$ respectively. All MOLAE concentrations had significantly reduced PL and RL of the C. lanatus (Figure 1c and d). Actually, at control level, PL and RL were 3.6 and $5.65 \mathrm{~cm}$, comparable to 0.59 and $0.85 \mathrm{~cm}$ respectively at $10 \%$ MOLAE concentration. The concentration $2.5 \%$ aqueous extracts reduced plumule and radicle growth of C. lanatus up to 28.73 and $22.48 \%$ compared to control. Simple linear regression was obtained by plotting GP, PT, PL and RL of the test species versus the different concentrations of MOLAE. The coefficient of determination $\left(\mathrm{R}^{2}\right)$ for data at the $7^{\text {th }}$ day attained a value of about $0.94,0.97,0.97$ and 0.99 for C. lanatus, respectively.
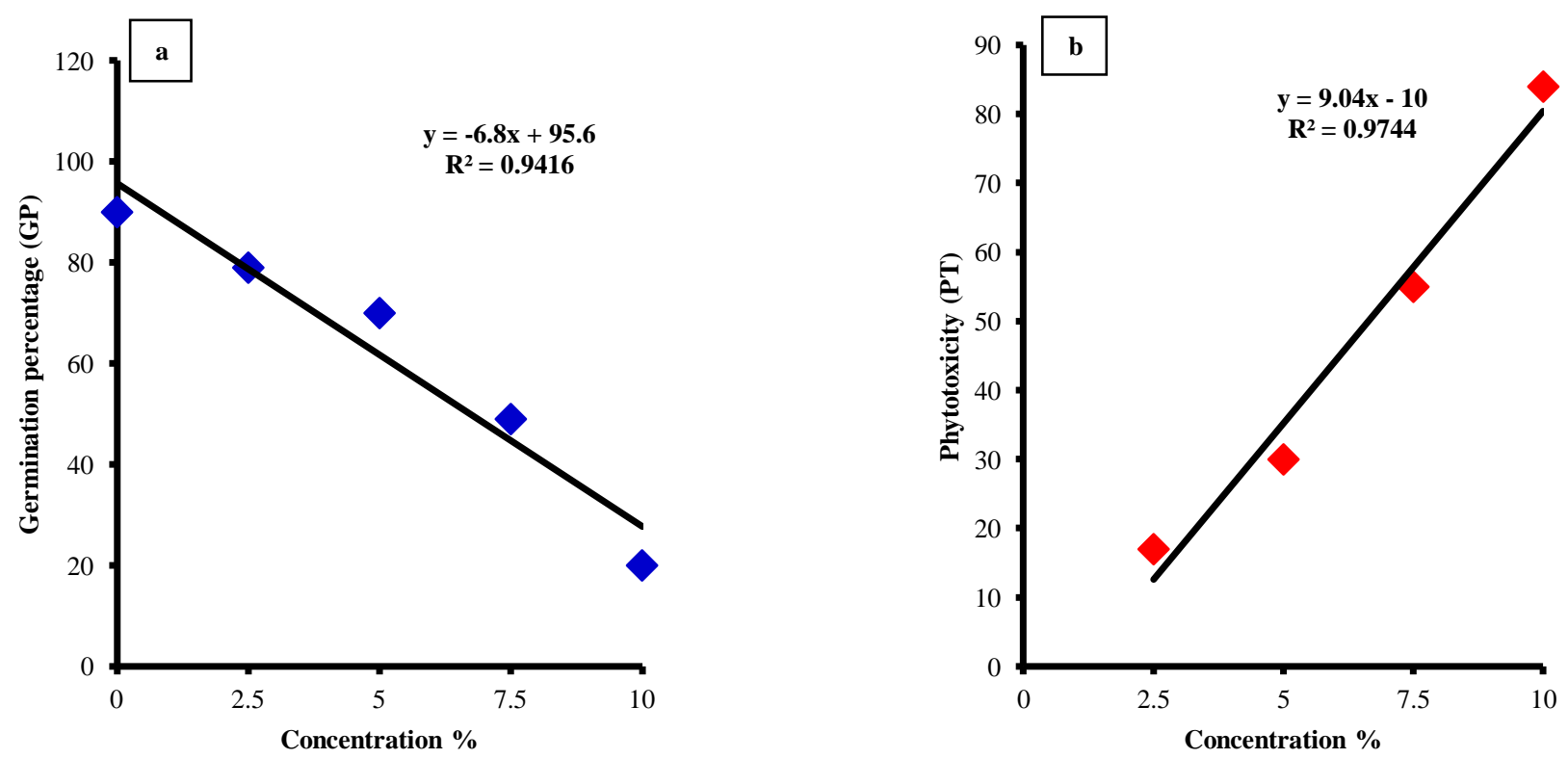


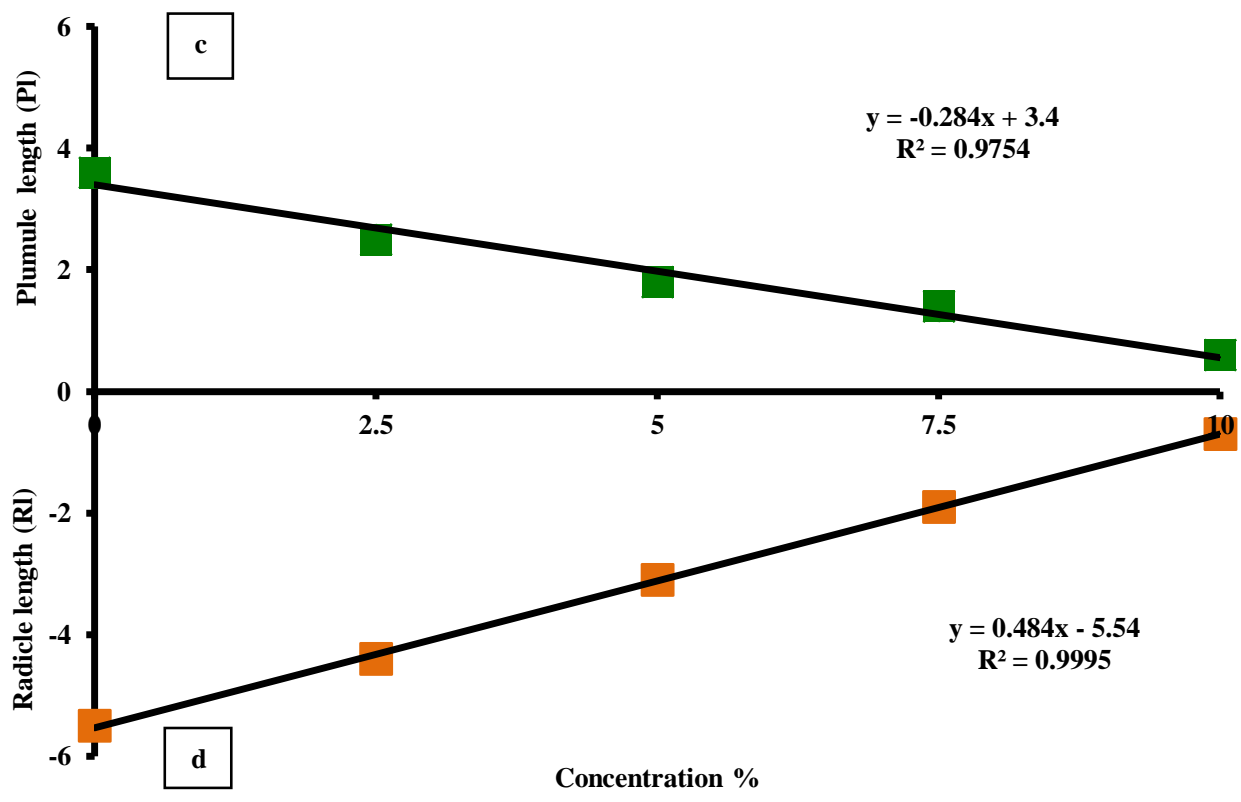

Fig. 1: Regression lines for the allelopathic effect of different concentrations of Moringa oleifera leaves aqueous extract (MOLAE) on germination percentage (GP), phytotoxicity (PT), plumule (PL) and radicle (RL) lengths of Citrullus lanatus seeds at the seventh day after sowing. Data are means of three replicates.

The values of seed germination index (SGI) and energy of germination (GE), decreased clearly as MOLAE concentration increased (Table1). The two parameters significantly decreased from 21.8 and 0.80 for control to 4.7 and 0.2 for 10\% MOLAE respectively. Similarly, SGI and GE decreased visibly in response to 5 and 7.5\% MOLAE, the values were 14 and 10.5 as well as 0.4 and 0.3 , respectively. At $2.5 \%$ extract level, SGI attained a value of about 16.8 while GE exhibited a value of 0.50 .

Table 1. Allelopathic effect of different concentrations of Moringa oleifera leaves aqueous extract (MOLAE) on seed germination index (SGI) and energy of germination (GE) of Citrullus lanatus seeds. Data are means of three replicates.

\begin{tabular}{|c|c|c|}
\hline Treatment (\%) & Seed Germination Index (SGI) & $\begin{array}{c}\text { The energy of Germination } \\
\text { (GE) }\end{array}$ \\
\hline $\mathbf{0}$ & $21.80^{\mathrm{e}}$ & $0.80^{\mathrm{b}}$ \\
\hline $\mathbf{2 . 5}$ & $16.80^{\mathrm{d}}$ & $0.50^{\mathrm{b}}$ \\
\hline $\mathbf{5}$ & $14.00^{\mathrm{c}}$ & $0.40^{\mathrm{a}}$ \\
\hline $\mathbf{7 . 5}$ & $10.50^{\mathrm{b}}$ & $0.30^{\mathrm{a}}$ \\
\hline $\mathbf{1 0}$ & $4.70^{\mathrm{a}}$ & $0.20^{\mathrm{a}}$ \\
\hline
\end{tabular}

Different letters within each column for the two types of extract indicate a significant difference at probability level $\leq 0.05$ according to ONE -WAY ANOVA.

\subsection{Growth Bioassay}

\subsubsection{Soil analysis}

The routine analyses for soil-applied in the current study are listed in Table 2. In general, the results showed that soil texture is represented by $24 \%$ clay, $58 \%$ sand, $18 \%$ silt indicating a sandy clay loam soil. The soil comprises considerable content of organic matter (about 10\%), $\mathrm{pH}$ value was about 7.8 and electrical conductivity (EC), which indicates the total soluble salts is about $2.72 \mathrm{dSm}^{-1}$. Concerning the essential elements the nitrogen, phosphorus, potassium contents were 1.1, 0.5 and $3.5 \mathrm{mg} \mathrm{g}^{-1}$, respectively.

Table 2. Variation in some physical and chemical characteristics of the soil-applied to carry out the pot experiment. Considering that, a: $\mathrm{dSm}^{-1}, \mathrm{~b}: \%$ and c: $\mathrm{mg} \mathrm{g}^{1}$.

\begin{tabular}{|c|c|}
\hline Physical properties & Range \\
\hline Texture & Sandy clay loam \\
\hline Clay $^{\mathrm{b}}$ & $24.00-26.90$ \\
\hline Sand $^{\mathrm{b}}$ & $58.00-61.28$ \\
\hline Silt $^{\mathrm{b}}$ & $18.00-19.23$ \\
\hline Chemical properties $^{\mathrm{a}}$ & \\
\hline Electrical conductivity $^{\mathrm{a}}$ & $2.72-2.82$ \\
\hline Organic matter $^{\mathrm{b}}$ & $9.08-10.00$ \\
\hline
\end{tabular}




\begin{tabular}{|c|c|}
\hline $\mathrm{pH}$ & $7.82-9.01$ \\
\hline Free carbon ${ }^{b}$ & $1.50-1.53$ \\
\hline $\mathrm{N}^{\mathrm{c}}$ & $1.100-1.104$ \\
\hline $\mathrm{P}^{\mathrm{c}}$ & $0.520-0.527$ \\
\hline $\mathrm{K}^{\mathrm{c}}$ & $3.50-3.98$ \\
\hline $\mathrm{Ca}^{\mathrm{c}}$ & $15.40-17.34$ \\
\hline $\mathrm{Mg}^{\mathrm{c}}$ & $1.40-1.42$ \\
\hline $\mathrm{Cl}^{\mathrm{c}}$ & $15.25-16.45$ \\
\hline $\mathrm{CO}_{3}{ }^{\mathrm{c}}$ & $35.00-37.21$ \\
\hline $\mathrm{SO}_{4}{ }^{\mathrm{c}}$ & $18.70-19.38$ \\
\hline
\end{tabular}

\subsubsection{Seedling weights and water content}

The fresh and dry weights of shoots and roots of $C$. lanatus seedlings gradually reduced with significant values in response to the increase in MOLCP relative to control (Table 3). The reduction in fresh shoot weight achieved higher percentages than that occurred in the root. The highest reduction in the shoot $(70 \%)$ and root $(50 \%)$ fresh weight was recorded under the highest concentration treatment. The highest reduction in dry shoot weight $(68 \%)$ and root dry weight $(65 \%)$ was recorded at $10 \%$ concentration treatment compared to the control. The seedling water content of $C$. lanatus was reduced gradually with the concentration of MOLAE and recorded the highest reduction (18\%) under the highest treatment of M. oleifera as related to the control.

Table 3. Allelopathic effect of different concentrations of Moringa oleifera leaves crude powder (MOlCP) on seedling fresh and dry weight in addition to the water content of Citrullus lanatus in the pot experiment.

\begin{tabular}{|c|c|c|c|c|c|c|c|}
\hline \multirow{2}{*}{ Treatment (\%) } & \multicolumn{2}{|c|}{ Seedling fresh weight (g) } & \multicolumn{2}{|c|}{ Seedling Dry weight (g) } & \multirow{2}{*}{ Seedling water content (\%) } \\
\cline { 2 - 6 } & Shoot & Root & Total weight & Shoot & Root & Total weight & \\
\hline Control & $10.12^{\mathrm{a}}$ & $5.42^{\mathrm{a}}$ & $15.54^{\mathrm{a}}$ & $4.21^{\mathrm{a}}$ & $1.98^{\mathrm{a}}$ & $6.19^{\mathrm{a}}$ & $60.16^{\mathrm{a}}$ \\
\hline 2.5 & $7.65^{\mathrm{b}}$ & $4.35^{\mathrm{b}}$ & $12.00^{\mathrm{b}}$ & $3.54^{\mathrm{b}}$ & $1.45^{\mathrm{b}}$ & $4.99^{\mathrm{b}}$ & $58.41^{\mathrm{b}}$ \\
\hline 5 & $5.67^{\mathrm{c}}$ & $3.45^{\mathrm{c}}$ & $9.12^{\mathrm{c}}$ & $1.70^{\mathrm{c}}$ & $0.94^{\mathrm{c}}$ & $3.94^{\mathrm{c}}$ & $56.79^{\mathrm{c}}$ \\
\hline 10 & $3.02^{\mathrm{d}}$ & $2.98^{\mathrm{d}}$ & $6.00^{\mathrm{d}}$ & $1.36^{\mathrm{d}}$ & $0.70^{\mathrm{d}}$ & $2.06^{\mathrm{d}}$ & $49.00^{\mathrm{d}}$ \\
\hline
\end{tabular}

Different letters within each column indicate significant difference at $\mathrm{P} \leq 0.05$ according to ONE -WAY ANOVA.

\subsection{Seedling protein electrophoresis}

The electrograms of the $C$. lanatus specimens, which were exposed to allelopathic effects of $10 \%$ concentration levels of MOLAE in compare to control level, are illustrated in Plate 1. A total of 15 bands are produced at $10 \%$ concentration levels $C$. lanatus seedling attained the minimum values of bands of about 8 bands. On the other hand, the maximum values were achieved at control level of about 10 bands. Seedling profile protein showed 3 common bands at 206, 165 and 50 KDa without any specific bands. The studied specimens manifested the appearance and the disappearance of bands, as well as the alteration bands intensities (Table 4.) Both the appearance and disappearance of bands achieved values of about 12 bands at $10 \%$ concentration level. The genomic template stability (GTS \%) of C. lanatus reduced from $100 \%$ at control level to $20 \%$ at $10 \%$ concentration level of MOLAE.

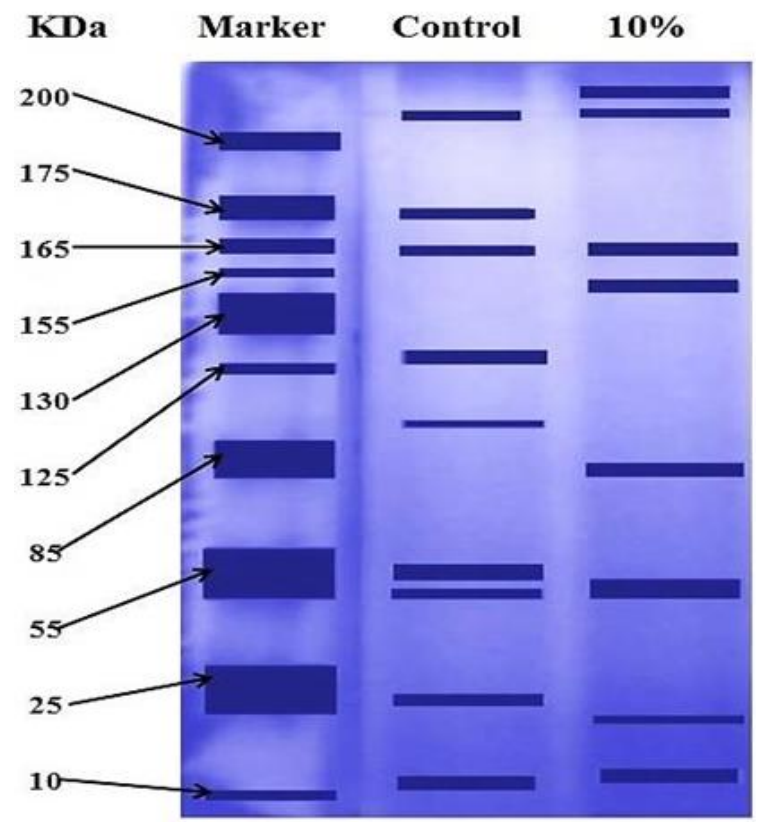


Plate 1. Banding patterns produced from the effect of $10 \%$ Moringa oleifera leaves aqueous extract (MOLAE) on Citrullus lanatus leaves run on SDS-PAGE gel. Samples from left to right: marker, control and allelopathy treatment.

Table 4. Changes of both total and polymorphic bands in Citrullus lanatus affected by $10 \%$ concentration Moringa oleifera leaves aqueous extract (MOLAE); a, indicates the appearance of new bands; $b$, indicates the disappearance of normal bands; $c$, decrease in band intensities; $d$, increase in band intensities; $a+b$, denotes polymorphic bands; $a+b+c+d$, varied band and GTS\%, Genomic template stability.

\begin{tabular}{|c|c|c|c|c|c|c|c|}
\hline \multirow{2}{*}{ Concentrations } & \multicolumn{9}{|c|}{ Bands } & \multirow{2}{*}{ GTS\% } \\
\cline { 2 - 8 } & $\mathbf{a}$ & $\mathbf{b}$ & $\mathbf{c}$ & $\mathbf{d}$ & $\mathbf{a + b}$ & $\mathbf{a + b + c + d}$ & \\
\hline Control & 0 & 0 & 0 & 0 & 0 & 0 & $100 \%$ \\
\hline $\mathbf{1 0 \%}$ & 5 & 7 & 1 & 2 & 12 & 15 & $20 \%$ \\
\hline
\end{tabular}

Genomic template stability (GTS \%) was calculated as the following:

GTS \% $=(1-a / n) \times 100$

Where a: average number of polymorphic bands detected in each treated sample, (polymorphism include the appearance of new bands and disappearance normal bands), n: total number of bands [22] .

\section{DISCUSSION}

Recently, multiple cropping systems have attained a global interest to maximize the productivity of cultivated areas at every single growing season to meet the food demand and to cope with the new approaches of using crops as biofuel source [23]. However, several allelochemicals may leach out from plant litter or fallen leaves upon rainfall or irrigation water, which may exert an auto- or poly-toxicity (growth malformation of the same or associated intercrops) depending on the type of the plant species [24]. Commonly, the effect is believed to concentration-dependent on inhibitory substances with a response threshold [25, 26].

In the present study, the GP of $C$. lanatus was significantly decreased with the increase in concentration grades of MOLAE. Specifically, GP decreased substantially at higher concentrations compared to the control. Abou-Zaid and El-Darier [9] reported that MOLAE achieved inhibition effect on the two field crops; Vicia faba and Zea mays. Similarly, Hossain et al. [27] assumed that different concentrations of plant organs extracts of $M$. oleifera have an inhibitory effect on Vigna radiata germination rate. Furthermore, Phiri and Mbewe [28] confirmed that addition of MOLAE significantly decreased GP of groundnut seed. On contrarily, Phiri [29] reported that MOLAE increased the germination rate of sorghum. Mahboobi and Heidarian [30] found that applications of Mint, Rosemary, Lavender and Yarrow decreased the germination percentage of tested weeds; Peganum harmala, Marobium alyssum, Amaranthus retroflexus. As well, the higher the concentration of Eucalyptus globulus plant extracts, the higher the influences on the germination of barley and teff plant species under laboratory condition [31].

SGI and GE decreased as a response to the regular application of higher MOLAE which are in consistence with those reported by El-Darier and Zein El-Dien [32] on tomato seeds versus Medicago sativa aqueous extract. El-Kenany et al. [8] reported a gradual decrease in the values of the two parameters for Lupinus termis seeds in response to the regular application of higher Nigella sativa seed cold and hot aqueous extract concentration levels.

A gradual decrease in plumule length (PL) of $C$. lanatus was noticed along with the gradual MOLAE concentrations as compared to the control. Explicitly, the higher concentrations of $M$. oleifera fresh leaves extract suppress some growth parameters of Euphorbia heterophylla more than the lower and the control [33].The reduction in PL of Chenopodium album and Portulaca oleracea upon application of Eucalyptus rostrata aqueous extract may be attributed to the presence of a diversity of allelochemicals in the extracts [34]. Moreover, Ashti et al. [35] found a significant reduction of shoot and radicle lengths of Vicia sativa, Sinapis arvensis, Vicia narbonensis and Cicer arietinum in response to aqueous seed extract of two types of Cicer arietinum.

PT values were notably different in response to changing the aqueous extract concentrations from 2.5 to $10 \%$. Al-Taisan [36] showed that all tested concentrations of Heliotropium bacciferum leaves extract initiated a general phytotoxic effect on seed germination and seedling growth of Oryza sativa and Teucrium polium. Recently, Ozobia [37] reported that Moringa extracts exert a significant effect on the growth performance of Solanum melongena.

The present study also indicated that fresh and dry weights of shoots and roots of $C$. lanatus seedling gradually reduced with significant values in response to the increase in the M. oleifera leaves aqueous extract as compared to control treatment. Ali and Mezori [38] tested the effects of aqueous extract of shoot and root of mixed crops Hibiscus esulentus, Sorghum bicolor, Helianthus annuus, Capsicum frutescens and Lycopersicon esculentum for their bioassay activity on the growth of same and other associated plants. Inhibition was more severe on dry weight than the lengths of tested plants. This may be either due to inhibition of ion uptake from soil solutions [39] or the plants being under stress, which resulted in the relatively taller root system. In a recent study by Kamel and Hammad [40], confirmed that fresh and dry weight of both wheat and canola were significantly reduced in response to different concentration of Acacia saligna leaf extract which may ascribe to allelochemicals retardation of cell division that consequently affects the produced plant biomass.

In general, abiotic or biotic stress induces metabolic responses as well as gene expression, including the production of stress proteins [41]. In the present study, the potential of seedling storage protein to assess the genetic diversity of Citrullus lanatus affected by $10 \%$ concentration of Moringa oleifera L. leaves aqueous extract. Seedling protein electrophoresis considers a very 
common method for separating proteins by electrophoresis uses a discontinuous polyacrylamide gel as a support medium and sodium dodecyl sulfate (SDS) to denature the proteins. The method is called sodium dodecyl sulfate-polyacrylamide gel electrophoresis (SDS-PAGE), the results showed that most of the extracted proteins of Citrullus lanatus seedling migrated in the range of $10 \mathrm{KDa}$ to $200 \mathrm{KDa}$.

In the current study, the seedling protein profiles achieve relatively instabilities as a result of allelochemicals. It is obvious through the estimation of the genomic template stability percentage, which is relatively low in comparison with the control. This is in concordance with El-Khawas and Shehata [42] and Hegazy et al. [43] that the seedling proteins decrease with the increase in the concentration of allelochemicals. This reduction may be due to the presence of phenolic compounds, which reduce the incorporation of phosphorus into DNA and RNA. Meanwhile, Baziramakenga et al. [44] and Padhy et al. [45] concluded that phenolic acids reduced the incorporation of certain amino acid into proteins and thus reduce the rate of protein synthesis.

Finally, the active constituents play a major role in the suppression of germination and growth of test species in response to $M$. oleifera. Dry leaves aqueous extract of $M$. oleifera contain tannins, saponins, carbohydrates, flavonoids, cardiac glycosides and alkaloids [46]. M. oleifera leaf and seed extracts performed by El-Rokiek et al. [47] revealed the presence of polyphenol in both extracts but in a double concentration in leaf extract than in seed extract while flavonoids are only present in leaf extract and absent in seed extract. The authors also postulated that polyphenol in both $M$. oleifera leaf and seed extracts is the main reason for growth inhibition of broad weed (Beta vulgaris) and narrow weed (Phalari minor). According to the data obtained from the present study on $M$. oleifera and other studies on $M$. peregrina [48] both species must be considered as an allelopathic species pretense risk in rotation or an intercropping or mixed cropping system. To alleviating its adverse effects on intercropping or subsequent crops, farmers should be conscious of leaves fallen from the mature trees and mixed with soil as well as the appropriate selection of the intercrops. As a result, we suggest the use of leaf litter trap (Figure 2) to prevent the expected allelopathic effects on the associated crop and the farmer can intercrop the watermelon safely with Moringa trees.
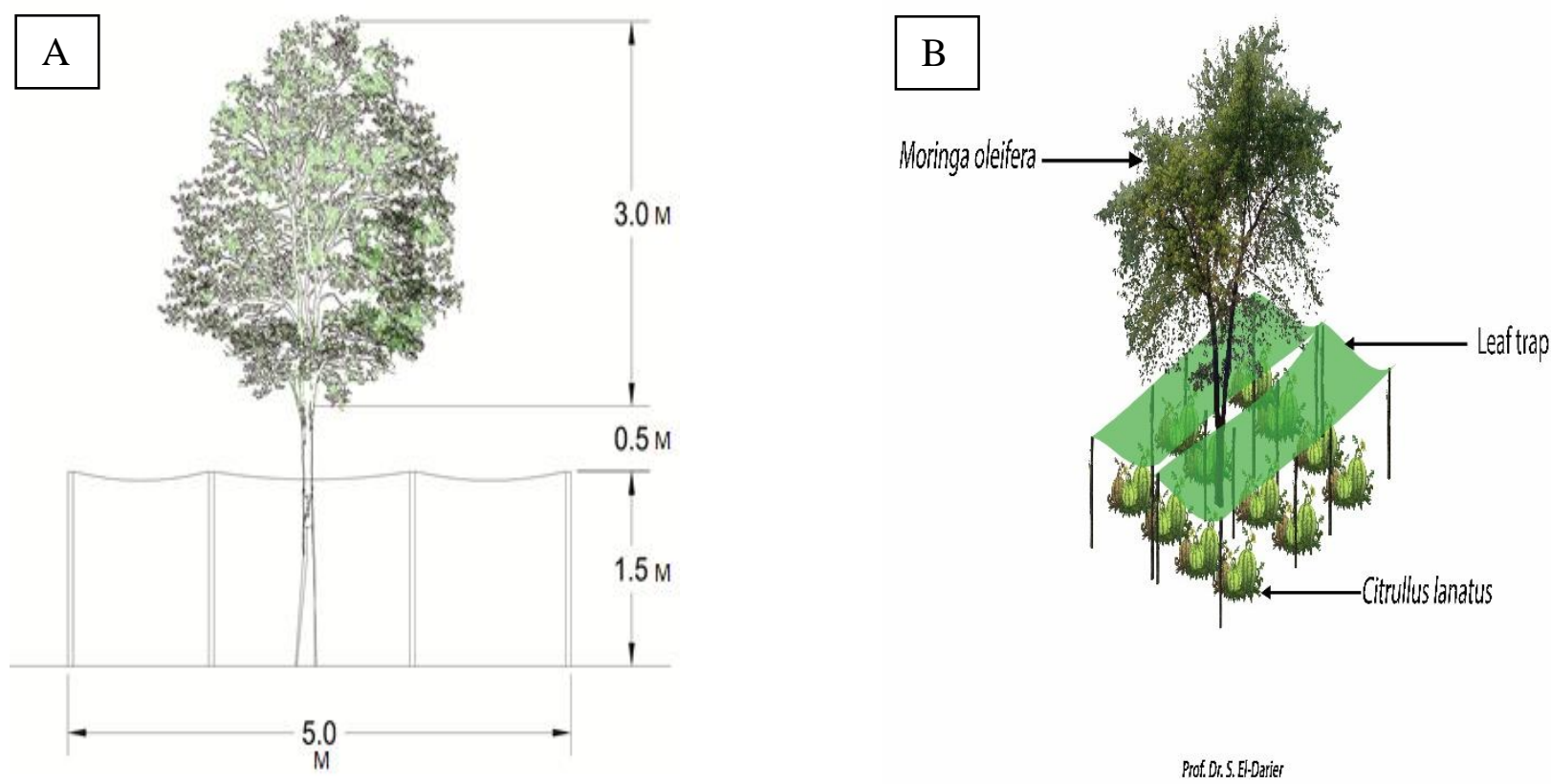

Fig. 2: Suggested leaf litter trap of Moringa oleifera to avoid its allelopathic effect on the understory. A: dimension of a single tree and proposed position of a litter trap. B: Design of mixed crop-tree plantation using leaf litter trap.

\section{CONCLUSION}

Intercropping is a common practice in trees plantation to maximize the economic outcomes of the cultivated area, awareness of the suitable plants that can be grown together without negative effects on their yield and productivity is of great importance. Moringa oleifera leaves extract showed phytotoxic effects on germination of $C$. lanatus, which makes their intercropping together is not economically suitable unless farmer use leaf litter trap to avoid fall of $M$. oleifera leaves protecting the associated crop from their negative allelopathic effects.

\section{CONFLICT OF INTEREST}

There are no conflicts of interest.

\section{REFERENCES}

1. Altieri, M.A., 1992. Agroecological foundations of alternative agriculture in California. Agriculture, Ecosystems and Environment, 39: 23-53. 
2. Jannoyera M. L., F. Le Bellecb, C. Lavignea, R. Achardc and E. Malézieux 2011. Ecological engineering: from concepts to applications Choosing cover crops to enhance ecological services in orchards: a multiple criteria and systemic approach applied to tropical areas. Procedia Environmental Sciences, $9104-112$.

3. Wiström, B., A.B. Nielsen, and M.C. Bjørn, 2018. Use of cover crops when establishing woody plantings. Department of Geosciences and Natural Resource Management, University of Copenhagen, Frederiks-berg. 50 pp.

4. Vinoth, B., R. Manivasagaperumal and S. Balamurugan, 2012. Phytochemical analysis and antibacterial activity of Moringa oleifera lam. International Research Journal of Biological Sciences, 2: 98-102.

5. Bhattacharya, A., P. Tiwari, P.K. Sahu and S. Kumar, 2018. A review of the phytochemical and pharmacological characteristics of Moringa oleifera. Journal of Pharmcy \& Bioallied Sciences; 10:181-91.

6. Geno, L. and B. Geno, 2001. Polyculture Production Principles, Benefits and Risks of Multiple Cropping Land Management Systems for Australia: A report for the Rural Industries Research and Development Corporation, 1-115.

7. Sathishkumar, A., G. Srinivasan, T. Ragavan, S. Thiyageshwari and N. Aananthi, 2017. Allelopathic Effect of Different Intercropping System and Tree Leaf Extract Spray on Weed Density, Dry Matter and Weed Control Efficiency in Irrigated Cotton. International Journal of Current Microbiology and Applied Sciences, 6 (6): 1322-1329.

8. El-Kenany, E.T., S.M. El-Darier, S.A. Kamal and N. Belgassem, 2014. The Probable Allelopathic Interference of Nigella sativa L. Seed Extracts with Lupinus termis L. Catrina, 9: 65-73.

9. Abou-Zeid, H.M. and S.M. EL-Darier, 2014b. Biological interactions between Moringa oleifera Lam. and two common food intercrops: growth and some physiological attributes. International Journal of Advanced Research, 2: 823-836.

10. Ahangar, F.A., R.J. Rao and K. Mamta, 2014. Allelopathic effect of aqueous extracts of neem (Azadiracta indica) and eucalyptus (Eucalyptus citroides) on the growth and germination of wheat (Triticum aestivum var-desi). Journal of Environmental Science and Engineering Technology, 1: 42-45.

11. Mona, H.S., H.H. Ahlam, A. Hamdah and S.A. Shroug, 2017. Allelopathic effect of Moringa oleifera leaves extract on seed germination and early seedling growth of Faba Bean (Vicia faba L.). International Journal of Agricultural Technology, 13(1):105-117.

12. Kamran, M., Z.A. Cheema, M. Farooq and A.U. Hassan, 2016. Influence of foliage applied allopathic water extracts on the grain yield, quality and economic returns of hybrid maize. International Journal of Agriculture \& Biology, 18: 577-583.

13. Tahir, N.A., K.O. Qader, H.A. Azeez and J.S. Rashid, 2018. Inhibitory allelopathic effects of Moringa oleifera Lamk plant extracts on wheat and Sinapis arvensis L. Allelopathy Journal, 44 (1): 35-48.

14. Macias, F.A., D. Castellano and J.M.G. Molinillo, 2000. Search for a standard phytotoxic bioassay for allelochemicals. Selection of target species. Journal of Agricultural and Food Chemistry, 48: 2512-2521.

15. Singh, H. P., D. R. Batish and R. K. Kohli, 2003. Allelopathic interactions and allelochemicals: new possibilities for sustainable weed management. Critical Reviews in Plant Sciences, 22: 239-311.

16. Scott, S.J., R.A. Jones and W.A. Williams, 1984. Review of data analysis methods for seed germination. Crop Science, 24: 1192-1199.

17. Farooq, M., S.M.A. Basra, K. Hafeez and N. Ahmad, 2005. Thermal hardening: a new seed vigor enhancement tool in rice. Acta Botanica Sinica, 47: 187-193.

18. Allen, S.E., H.M. Grimshaw, J.A. Parkinson and C. Quarmby, 1984. Chemical Analysis of Ecological Materials. Edited by S.E. Allen. Blackwell Scientific Publications, Oxford London, Edinburgh, Melbourne, 565 pp.

19. Laemmli, U.K., 1970. Cleavage of Structural Proteins during the Assembly of the Head of Bacteriophage T4. Nature, 227: $680-685$.

20. Steel, R.G.D., J.H. Torrie and D. Dickey, 1997. Principles and Procedure of Statistics. A Biometrical Approach $3^{\text {rd }}$ Ed. McGraw Hill Book Co. Inc., New York. pp. 352-358.

21. R Development Core Team, 2011. R: A language and environment for statistical computing. Vienna, Austria. ISBN: 3 900051-07- 0, available online at http://www.R-project.org/.

22. Cimino M.C. 2006. Comparative overview of current international strategies and guidelines for genetic toxicology testing for regulatory purposes. Environmental and Molecular Mutagenesis, 47:362-390.

23. Popp, J., Z. Lakner, M. Harangi-Rákos and M. Fári, 2014. The effect of bioenergy expansion: Food, energy, and environment. Renewable and Sustainable Energy Reviews,_32: 559-578.

24. Iqbal, M.A., 2014. Role of Moringa, Brassica and Sorghum Water Extracts in Increasing Crops Growth and Yield: A Review. American-Eurasian Journal of Agriculture and Environmental Sciences, 14: 1150-1158.

25. Ashrafi, Z.Y., S. Sadeghi, H.M. Alizade, H.R. Mashhadi and E.R. Mohamadi, 2009. Study of bioassay the allelopathical effect of Neem (Azadirachta indica) n-hexane, acetone and water-soluble extracts on six weeds. International Journal of Biology, 1: 71-77.

26. Batlang, U., and D.D. Shushu, 2007. Allelopathic activity of sunflower (Helianthus annuus L.) on growth and nodulation of bambara groundnut (Vigna subterranean (L.) verdc.). Journal of Agronomy, 6: 541-547.

27. Hossain, M.M., G. Miah, T. Ahame and N.S. Sarmin, 2012. Allelopathic effect of Moringa oleifera on the germination of Vigna radiata. International Journal of Agriculture and Crop Sciences, 4: 114-121.

28. Phiri, C. and D.N. Mbewe, 2009. Influence of Moringa oleifera leaf extracts on germination and early seedling survival of three common legumes. International Journal Agricultural Biology, 12: 315-317.

29. Phiri, C., 2010. Influence of Moringa oleifera leaf extracts on germination and early seedling development of major cereals. Agriculture and Biology Journal of North America, 1: 774-777. 
30. Mahboobi, N. and A.R. Heidarian, 2016. Allelopathic effects of medicinal plants on germination and seedling growth of some weeds. Journal of Fundamental and Applied Sciences, 8: 323-336.

31. Nega, F. and T. B. Gudeta, 2019. Allelopathic Effect of Eucalyptus globulus Labill. on Seed Germination and Seedling Growth of Highland Teff (Eragrostis tef (Zuccagni) Trotter)) and Barely (Hordeum vulgare L.). Journal of Experimental Agriculture International, 30(4): 1-12.

32. El-Darier, S.M. and M.H. Zein El-Dien, 2011. Biological activity of Medicago sativa L. (alfalfa) residues on germination efficiency, growth and nutrient uptake of Lycopersicon esculentum L. (tomato). Journal of Taibah University for Science, 5: 7-13.

33. Oluwafemi, A.B., 2014. Allelopathic effects of Moringa olifera on the germination and seedling survival of Euphorbia heterophylla L. Global Journal of Biology, Agriculture and Health Sciences, 1: 195-198.

34. Abou-Zeid, H.M. and S.M. EL-Darier, 2014a. Allelotoxic activity of Eucalyptus rostrata Schlecht. on seed germination and seedling growth of Chenopodium album L. and Portulaca oleracea L. International Journal of Agronomy and Agricultural Research, 4: 39-50.

35. Ashti, S. A., F. H. K. Hero, A.O. Dlshad and A.T. Nawroz, 2018. Response of some plant species towards the allelopathy of two types of chickpea (Cicer arietinum L.) seed extracts. Applied Ecology and Environmental Research 16 (6): 8119-8129.

36. Al-Taisan, W., 2014. Allelopathic effects of Heliotropium bacciferum leaf and roots on Oryza sativa and Teucrium polium. Life Science Journal, 11:41-50.

37. Ozobia, A.P., 2014. Comparative assessment of effect of Moringa extracts, NPK fertilizer and poultry manure on soil properties and growth performance of Solanium menlongina in Abuja. Journal of Agricultural and Crop Research, 5: 88 -93.

38. Ali, A.M. and H.A. Mezori, 2008. The allelopathic potential of some crops and vegetables in mixed farming in Dohuk governorate (1. water extract). Journal of Dohuk University, 11: 181-197.

39. Inderjit, 1997. Plant phenolics in allelopathy. Botanical Review , 62:186-202.

40. Kamel, M. and S.A. Hammad, 2015. The Allelopathic Effect of the Exotic Tree Acacia saligna on the Germination of Wheat and Canola. Ecologia Balkanica, 7: 103-112.

41. Maqbool, N., M.F. Abulwahid, Z.A. Cheema and K.H.M. Siddique, 2012. Allelopathy and abiotic stress interaction in crop plants, in Allelopathy Current Trends and Future Applications. Springer, Heidlberg PP. 451-468.

42. El-Khawas, S.A. and M.M. Shehata, 2005. The Allelopathic Potentialities of Acacia nilotica and Eucalyptus rostrata on Monocot (Zea mays L.) and Dicot (Phaseolus vulgaris L.) Plants. Biotechnology, 4: 23-34.

43. Hegazy, A.K., S.K. Goda and H.F. Farrag, 2007. Protein Expressions of Some Cultivated and Weed Plants in Response to Invasive Plant Mulching. Global Journal of Molecular Sciences, 2(1): 01-07.

44. Baziramakenga, R., G. Leroux, R. Simard and P. Nadeau, 1997. Allelopathic effects of phenolic acids on nucleic acids and protein levels in soybean seedlings. Canadian Journal of Botany, 75: 445-450.

45. Padhy, B.B., P.K. Patanaik and A.K. Tripathy, 2000. Allelopathic potential of Eucalyptus leaf litter leachates on germination and seedling growth of fingermillet. Allelopathy Journal, 7: 69-78.

46. Furo, N.A. and A.G. Ambali, 2012. An investigation into the phytochemical constituents of Moringa oleifera aqueous root extracts. Centre point Journal, 18: (1) 1-7.

47. EI-Rokiek, K. G., R. A. Eid, A. N. Shehata, and S. A. S. EI-Din. 2017. Evaluation of using Moringa oleifera on controlling weeds. i. Effect of leaf and seed water extracts of Moringa oleifera on broad and grassy weed associated Narcissus tazetta L. Agricultural Engineering International: CIGR Journal, Special issue: 45-52.

48. Aytah, A.A., 2017. Allelopathic effect of Moringa peregrina Forssk. on germination and early seedling development of two common food intercrops. International Journal of Current Microbiology and Applied Sciences, 6 (1): 161-167. 